Supporting Information

\title{
Potential-Dependent Adsorption and Orientation of meso-Substituted Porphyrins at Liquid|Liquid Interfaces \\ Studied by Polarization-Modulation Total Internal Reflection Fluorescence Spectroscopy
}

Sho Yamamoto, ${ }^{\dagger}$ Hirohisa Nagatani, ${ }^{*, \neq}$ Kotaro Morita $^{\ddagger}$ and Hisanori Imura ${ }^{\ddagger}$

${ }^{\dagger}$ Division of Material Chemistry, Graduate School of Natural Science and Technology, Kanazawa University, Kakuma, Kanazawa 920-1192, Japan

‡ Faculty of Chemistry, Institute of Science and Engineering, Kanazawa University, Kakuma, Kanazawa 920-1192, Japan

*To whom correspondence should be addressed: H. Nagatani

Tel: +81 76264 5692; FAX: +81 76264 6059; E-mail: nagatani@se.kanazawa-u.ac.jp 


\section{S1. Polarization modulation efficiency of the excitation beam.}

The polarization modulation efficiency $\left(P_{\mathrm{m}}\right)$ of a liquid crystal retarder (LCR) in the present experimental setup was defined as the fraction of the p- or s-polarized component in the excitation beam through LCR. The intensities of p- and s-polarized incident beams, $I^{\mathrm{p}}$ and $I^{\mathrm{s}}$, were measured by a Glan-Thompson prism (Sigma Koki, GTPC-10-33SN) and a Si photodiode (Hamamatsu Photonics, S1133-01) placed after LCR. As shown in Figure S1, the maximum $I^{\mathrm{P}}$ and $I^{\mathrm{S}}$ were observed under respective polarization conditions of LCR. The $P_{\mathrm{m}}$ values in the pand s-polarized modes, $P_{\mathrm{m}}^{\mathrm{p}}$ and $P_{\mathrm{m}}^{\mathrm{s}}$, are expressed by eqs. S1 and $\mathrm{S} 2$ under respective polarization modes, respectively.

$$
\begin{aligned}
& P_{\mathrm{m}}^{\mathrm{p}}=\frac{I^{\mathrm{p}}}{I^{\mathrm{p}}+I^{\mathrm{s}}} \\
& P_{\mathrm{m}}^{\mathrm{s}}=\frac{I^{\mathrm{s}}}{I^{\mathrm{p}}+I^{\mathrm{s}}}
\end{aligned}
$$

The value of $P_{\mathrm{m}}\left(=P_{\mathrm{m}}^{\mathrm{p}}=P_{\mathrm{m}}^{\mathrm{s}}\right)$ was obtained as 0.95 indicating that a $5 \%$ of the s-polarized component remains in the p-polarization mode of LCR or vice versa.
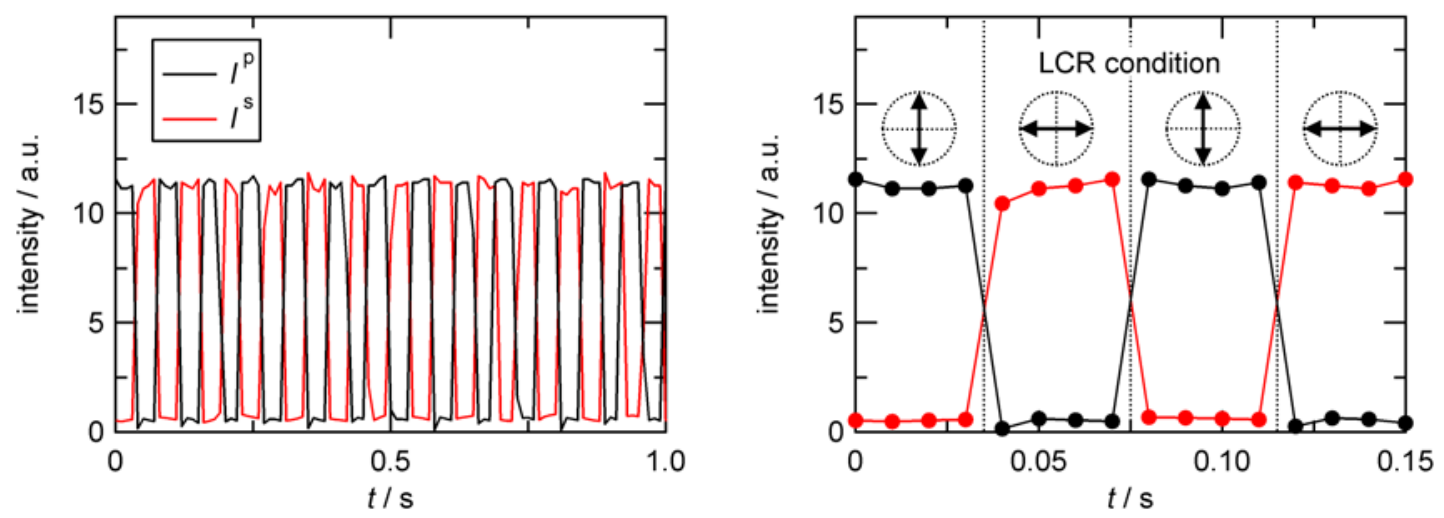

Figure S1. Typical time dependences of polarization-modulated light intensity through LCR at $13 \mathrm{~Hz}$. The black and red lines refer to the intensities of the p- and s-polarized components of the excitation beam. 
S2. Dependences of the fluorescence intensity on the linear polarization of excitation beam and molecular orientation

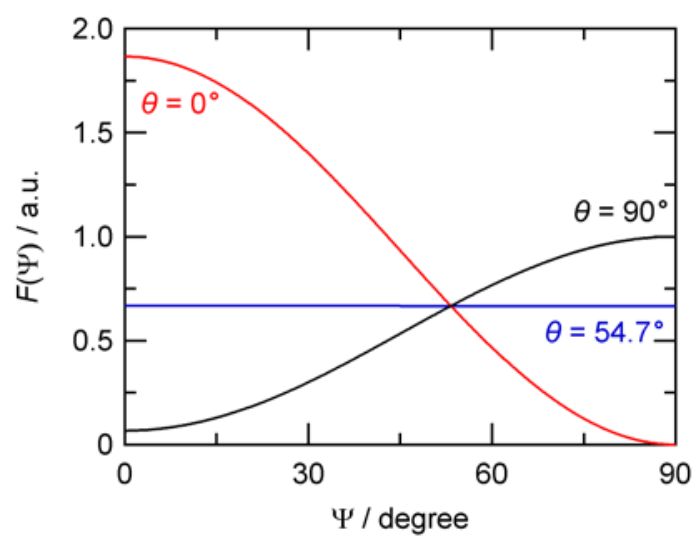

Figure S2. Polarization angle dependence of the fluorescence intensity $(F(\Psi))$ calculated from eq. 1. The angle of linear polarization of excitation beam $(\Psi)$ was defined as the angle with respect to the interface normal, where $0^{\circ}$ and $90^{\circ}$ relate to the p- and s-polarization, respectively. The orientation angle $(\theta)$ was taken as $0^{\circ}, 54.7^{\circ}$ and $90^{\circ}$. The values of other parameters were taken as $C=1, \alpha=75^{\circ}$, and $\theta=0^{\circ}, 54.7^{\circ}, 90^{\circ}$, respectively.

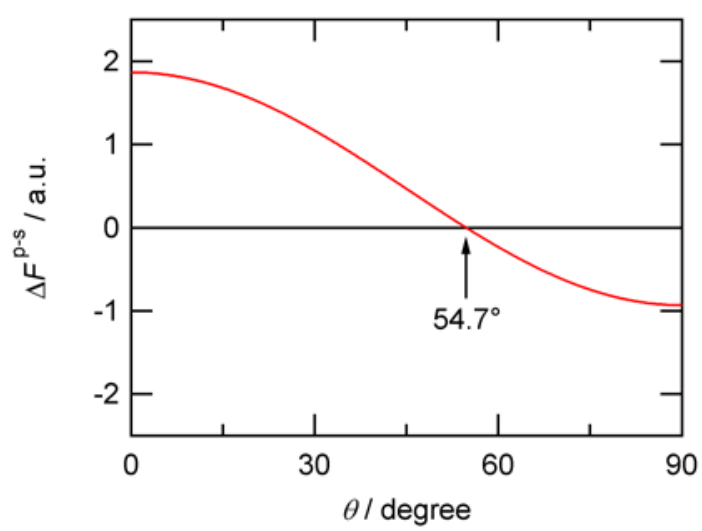

Figure S3. Orientation angle dependence of PM-TIRF signal ( $\left.\Delta F^{\mathrm{p}-\mathrm{s}}\right)$ calculated from eqs. 1 and 5. The orientation angle $(\theta)$ of an adsorbed molecule was varied between $0^{\circ}$ and $90^{\circ}$. The values of other parameters were taken as $C=1, \alpha=75^{\circ}$ and $P_{\mathrm{m}}=1$, respectively. 


\section{S3. Ac voltammetric responses for ion transfer of $\mathrm{H}_{2} \mathrm{TMPyP}^{4+}$ and $\mathrm{H}_{2} \mathrm{TPPS}^{4-}$}

The ac voltammograms for $\mathrm{H}_{2} \mathrm{TMPyP}^{4+}$ and $\mathrm{H}_{2} \mathrm{TPPS}^{4-}$ at the water|DCE interface are shown in Figure S4. The well-defined ion transfer responses of $\mathrm{H}_{2} \mathrm{TMPyP}^{4+}$ were obtained at around $\Delta_{0}^{\mathrm{w}} \phi_{\mathrm{H}_{2} \mathrm{TMPyP}^{\mathrm{a}+}}^{\mathrm{s}^{\prime}}=0.07 \mathrm{~V}$ (Figure S4a). On the other hand, a significant increase of the real $\left(Y_{\mathrm{re}}\right)$ and imaginary $\left(Y_{\mathrm{im}}\right)$ components of the admittance was measured in the $\mathrm{H}_{2} \mathrm{TPPS}^{4-}$ system at potentials prior to the ion transfer potential, i.e. $\Delta_{0}^{\mathrm{w}} \phi_{\mathrm{H}_{2} \mathrm{TPPS}^{\mathrm{a}}}^{\mathrm{o}^{4}}(=-0.20 \mathrm{~V})<\Delta_{0}^{\mathrm{w}} \phi$, which is associated with specific adsorption of $\mathrm{H}_{2} \mathrm{TPPS}^{4-}$ at the interface (Figure S4b). These results indicate that $\mathrm{H}_{2} \mathrm{TPPS}^{4-}$ is preferably adsorbed at the interface in comparison with $\mathrm{H}_{2} \mathrm{TMPyP}^{4+}$.,
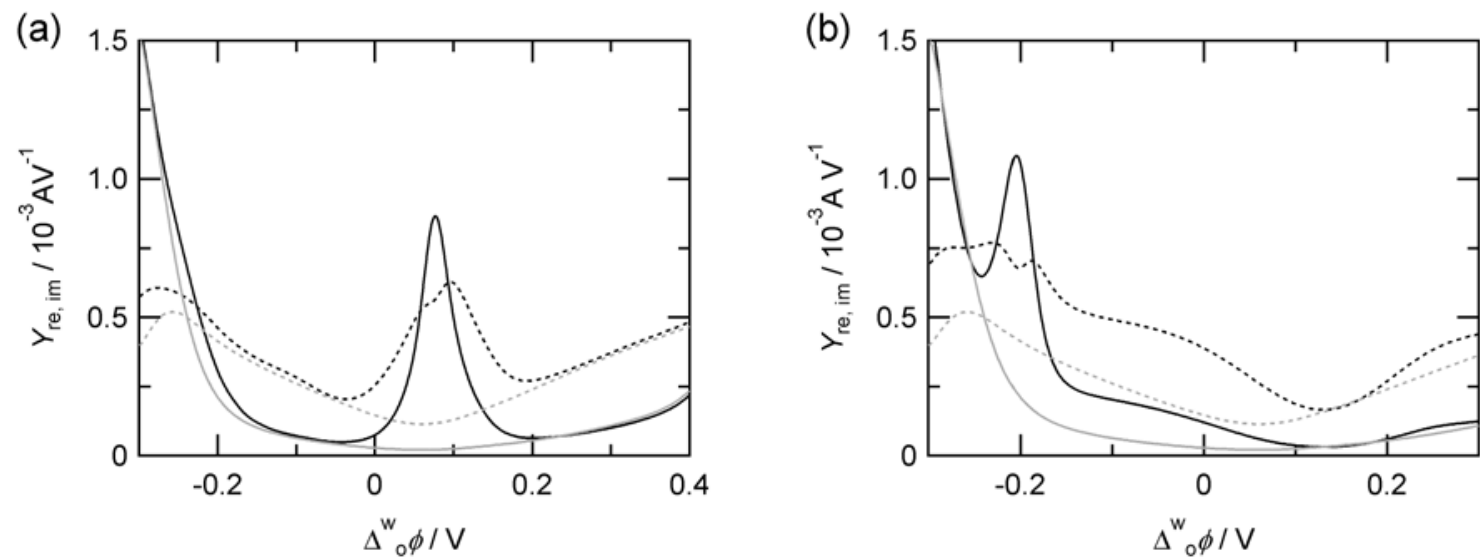

Figure S4. Real (solid line) and imaginary (dashed line) components of the admittance measured for (a) $\mathrm{H}_{2} \mathrm{TMPyP}^{4+}$ and (b) $\mathrm{H}_{2} \mathrm{TPPS}^{4-}$ at the water|DCE interface. The gray lines depict the admittances in the absence of the porphyrin. The potential modulation was $10 \mathrm{mV}$ at $7 \mathrm{~Hz}$. 


\section{S4. CVs and PM-TIRF responses for the simple transfer of tris(2,2'- bipyridine)ruthenium(II) (Ru(bpy) $3^{2+}$ ) across the water|DCE interface}

In order to clarify the surface sensitivity of the PM-TIRF technique, we applied the PM-TIRF spectroscopy to the tris(2,2'-bipyridine)ruthenium(II) $\left(\mathrm{Ru}(\mathrm{bpy}) 3_{3}{ }^{2+}\right)$ system. $\mathrm{Ru}(\mathrm{bpy})_{3}{ }^{2+}$ is an efficient fluorescent dye and it has been studied at the polarized water|DCE interface, ${ }^{3,4}$ in which $\mathrm{Ru}(\mathrm{bpy}) 3^{2+}$ exhibited a quasi-reversible ion transfer feature without the interfacial adsorption. The formal transfer potential was observed as $\Delta_{0}^{\mathrm{w}} \phi_{\mathrm{Ru}(\mathrm{bpy})_{3}{ }^{2+}}^{\mathrm{o}^{+}}=-0.10 \mathrm{~V}$ in the voltammetric measurements (Figure S5a). A $D_{3}$ symmetry of $\mathrm{Ru}(\mathrm{bpy})_{3}{ }^{2+}$ ensures independence of the fluorescence intensity on linear polarizations of the excitation beam, even if $\mathrm{Ru}(\mathrm{bpy}) 3^{2+}$ is adsorbed at the interface. The $\mathrm{Ru}(\mathrm{bpy}) 3_{3}{ }^{2+}$ system is therefore suitable to examine the selectivity of the PM-TIRF technique for the species "oriented” at the interface. As shown in Figure S5b, the PM-TIRF signals $\left(\Delta F^{\mathrm{p}-\mathrm{s}}\right)$ were almost constant in the whole potential region and negligibly small in comparison with the total fluorescence intensity $\left(F_{\text {total }}\right)$. In the absence of the interfacial adsorption, eq. (7) is simplified to $F_{\text {total }}=F_{\text {bulk }}$. Thus, $F_{\text {total }}$ at $\Delta_{0}^{\mathrm{w}} \phi<\Delta_{\mathrm{o}}^{\mathrm{w}} \phi_{\mathrm{Ru}(\mathrm{opy})_{3}{ }^{2+}}^{{ }^{\circ}}$ is identical to the
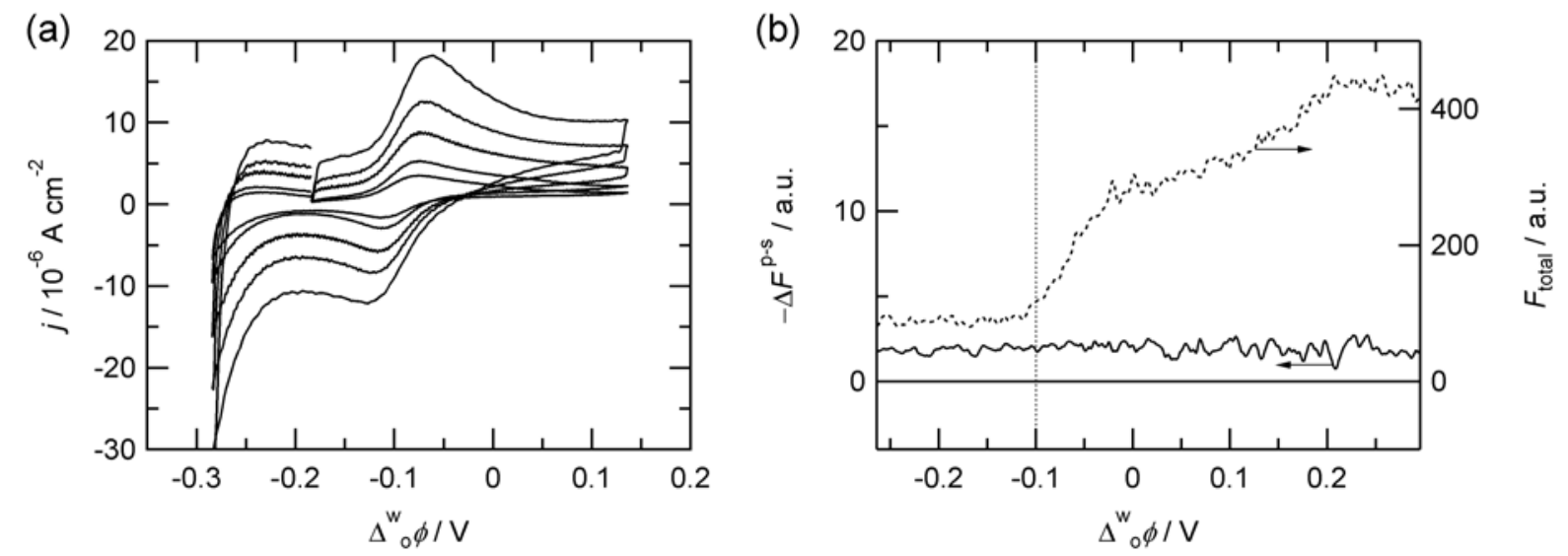

Figure S5. (a) Typical cyclic voltammograms and potential dependence of (b) PM-TIRF responses $\left(\Delta F^{\mathrm{p}-\mathrm{s}}\right)$ measured for $\mathrm{Ru}(\mathrm{bpy})_{3}{ }^{2+}$ at the water|DCE interface. The potential sweep rates were (a) 10, 20, 50, 100 and $200 \mathrm{mV} \mathrm{s}^{-1}$, (b) $5 \mathrm{mV} \mathrm{s}^{-1}$. The concentration of Ru(bpy) ${ }^{2+}$ derivatives in the aqueous phase was $2.0 \times 10^{-5} \mathrm{~mol} \mathrm{dm}^{-3}$. The $\mathrm{pH}$ values of the aqueous phase were $\mathrm{pH}$ 7.0. The excitation and detected emission wavelengths were $404 \mathrm{~nm}$ and $609 \mathrm{~nm}$, respectively. The vertical dotted line indicates $\Delta_{\mathrm{o}}^{\mathrm{w}} \phi_{\mathrm{Ru}(\mathrm{bpy})_{3}{ }^{2+}}^{\mathrm{o}^{+}}=-0.10 \mathrm{~V}$. 
fluorescence from the bulk aqueous phase and the significant increment of $F_{\text {total }}$ at $\Delta_{0}^{\mathrm{w}} \phi_{\mathrm{Ru}(\mathrm{bpy})_{3}{ }^{2+}}^{\mathrm{o}^{\mathrm{j}}}<\Delta_{0}^{\mathrm{w}} \phi$ associates with the fluorescence from $\mathrm{Ru}(\mathrm{bpy})_{3}{ }^{2+}$ transferred into the organic phase. The potential dependence of $F_{\text {total }}$ clearly showed that the fluorescence from the bulk organic phase effectively increases only at potentials beyond $\Delta_{0}^{\mathrm{w}} \phi^{\circ}$. It is noteworthy that $\Delta F^{\mathrm{p}-\mathrm{s}}$
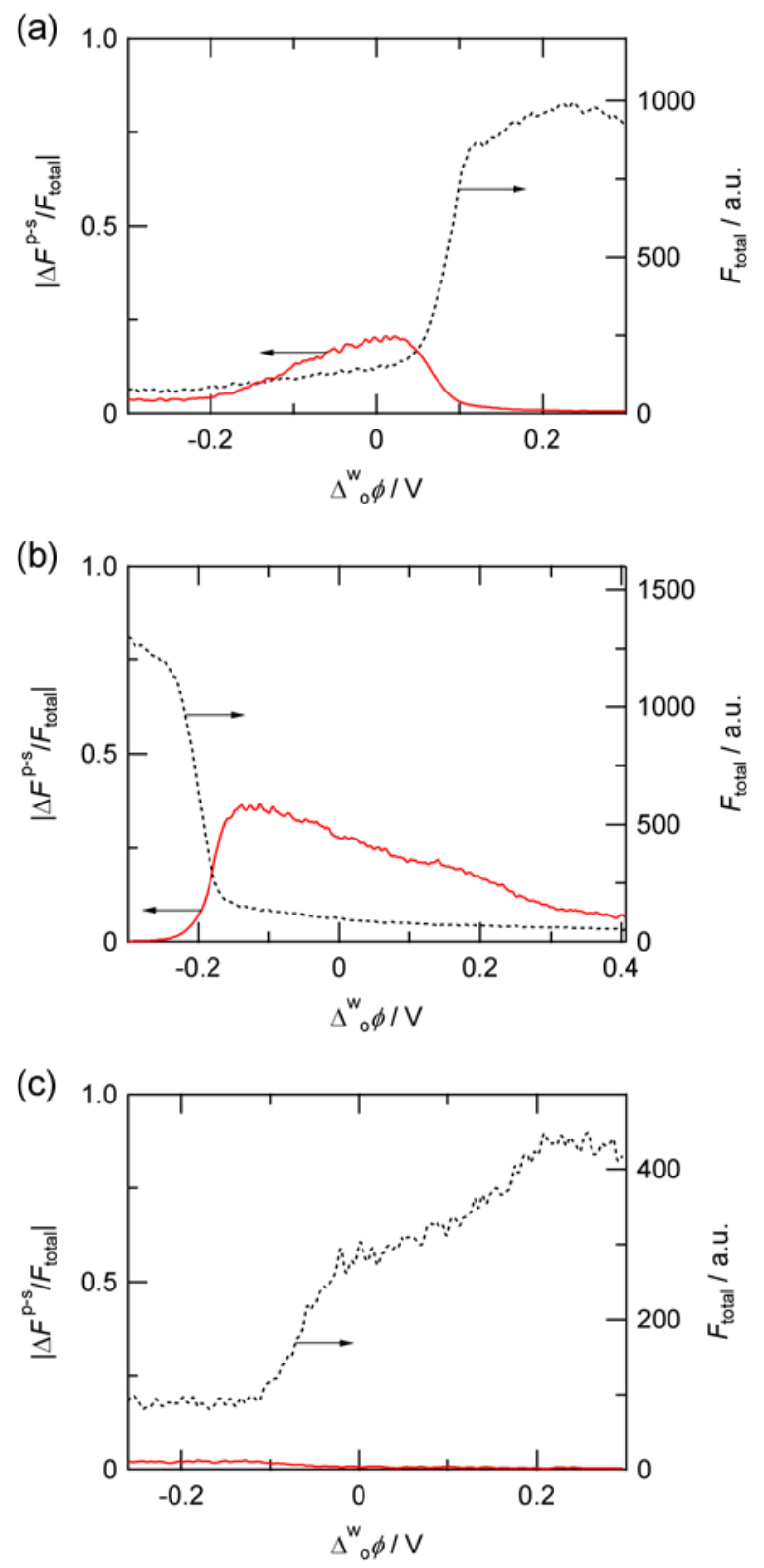

Figure S6. Potential dependences of $\left|\Delta F^{\mathrm{p}-\mathrm{s}} / F_{\text {total }}\right|$ for (a) $\mathrm{H}_{2} \mathrm{TMPyP}^{4+}$, (b) $\mathrm{H}_{2} \mathrm{TPPS}^{4-}$ and (c) $\mathrm{Ru}(\mathrm{bpy}) 3^{2+}$ systems. The dotted lines depict $F_{\text {total. }}$. 
was also independent on the $F_{\text {total }}$ value consisting of the fluorescence intensities from both bulk solutions and interfacial region. Figure $\mathbf{S 6}$ shows the relative intensity of $\Delta F^{\mathrm{p}-\mathrm{s}}$ with respect to $F_{\text {total }},\left|\Delta F^{\mathrm{p}-\mathrm{s}} / F_{\text {total }}\right|$. The $\left|\Delta F^{\mathrm{p}-\mathrm{s}} / F_{\text {total }}\right|$ values observed for Ru(bpy) ${ }^{2+}$ were much smaller than those for $\mathrm{H}_{2} \mathrm{TMPyP}^{4+}$ or $\mathrm{H}_{2} \mathrm{TPPS}^{4-}$. These experimental results clearly demonstrate that only the species which have the excitation dipole moment oriented at the interface can generate strong PM-TIRF signals. 


\section{S5. PM-TIRF responses of $\mathrm{H}_{2} \mathrm{TMPyP}^{4+}$ in the presence of Span 20}
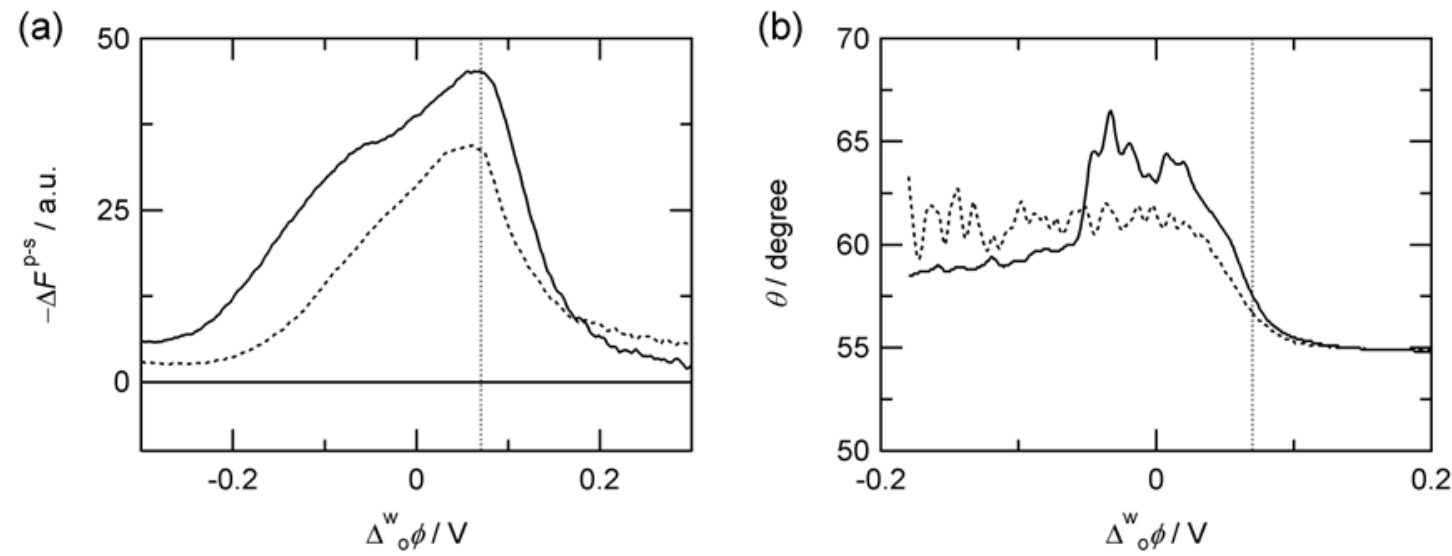

Figure S7. Potential dependences of (a) PM-TIRF ( $\Delta F^{\mathrm{p}-\mathrm{s}}$ ) and (b) orientation angle ( $\theta$ ) estimated for $\mathrm{H}_{2} \mathrm{TMPyP}^{4+}$ in the presence of Span 20. The solid and dashed lines relate to the $\mathrm{H}_{2} \mathrm{TMPyP}^{4+}$ systems in the presence and absence of $1.0 \times 10^{-3} \mathrm{~mol} \mathrm{dm}^{-3}$ Span 20 in the organic phase. The excitation and detected emission wavelengths were $404 \mathrm{~nm}$ and $660 \mathrm{~nm}$, respectively. The vertical dotted lines denote the ion transfer potential of $\mathrm{H}_{2} \mathrm{TMPyP}^{4+}\left(\Delta_{\mathrm{o}}^{\mathrm{w}} \phi_{\mathrm{H}_{2} \mathrm{TMPyP}^{\prime}}^{\mathrm{i}}=0.07 \mathrm{~V}\right)$.

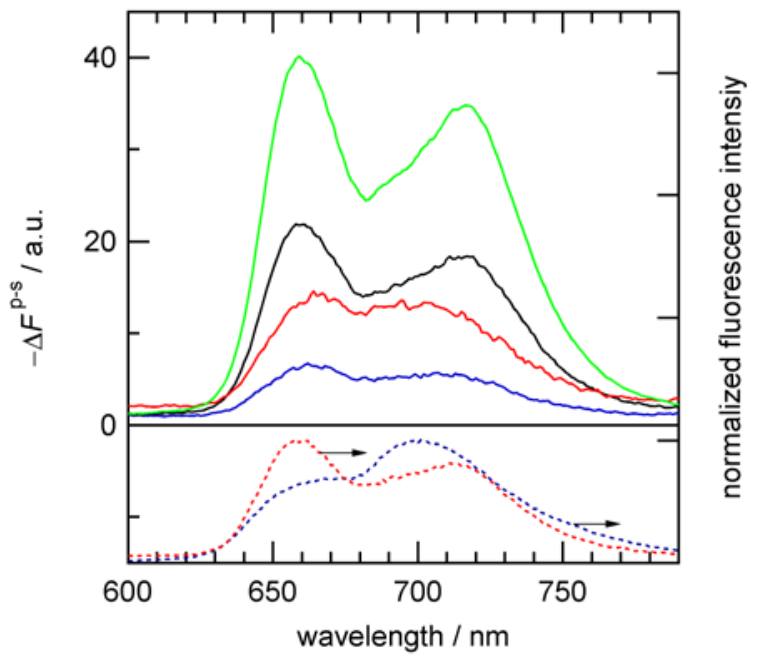

Figure S8. Potential dependent PM-TIRF spectra for $\mathrm{H}_{2} \mathrm{TMPyP}^{4+}$ at the water|DCE interface in the presence of Span 20. The blue, black, green and red solid lines depict PM-TIRF spectra measured at $-0.27 \mathrm{~V},-0.15 \mathrm{~V}-0.06 \mathrm{~V}$, and $0.19 \mathrm{~V}$, respectively, in the presence of $1.0 \times 10^{-3}$ mol dm${ }^{-3}$ Span 20 in the organic phase. The blue and red dashed lines refer to normalized fluorescence spectra measured in the aqueous and organic solutions. 
Table S1. Fluorescence maximum wavelengths $\left(\lambda_{\max }\right)$ of $\mathrm{H}_{2} \mathrm{TMPyP}^{4+}$ at the water|DCE interface in the presence of Span 20 in the organic phase.

\begin{tabular}{lrll}
\hline & \multicolumn{3}{c}{$\mathrm{H}_{2} \mathrm{TMPyP}^{4+}$ system } \\
\cline { 2 - 4 } & $\Delta_{\mathrm{o}}^{\mathrm{w}} \phi / \mathrm{V}$ & $\lambda_{\max } / \mathrm{nm}$ & $R_{\mathrm{F}}{ }^{a}$ \\
\hline interface & 0.19 & 663,704 & 1.1 \\
& -0.06 & 659,715 & 1.2 \\
& -0.15 & 660,714 & 1.3 \\
& -0.27 & 662,708 & 1.2 \\
\hline aqueous phase $^{b}$ & & 660,702 & 0.69 \\
organic phase $^{b}$ & & 659,712 & 1.2 \\
\hline
\end{tabular}

${ }^{a}$ The peak intensity ratio of the first and second fluorescence peaks. ${ }^{b}$ The fluorescence maximum wavelengths measured in the aqueous and organic solutions.

\section{REFERENCES}

(1) Nagatani, H.; Ozeki, T.; Osakai, T. J. Electroanal. Chem. 2006, 588, 99-105.

(2) Nagatani, H. In Handbook of Porphyrin Science, Kadish, K. M.; Smith, K. M.; Guilard, R., Eds.; World Scientific Publishing Co.: Singapore, 2014, pp 51-96.

(3) Ding, Z.; Wellington, R. G.; Brevet, P. F.; Girault, H. H. J. Electroanal. Chem. 1997, 420, 35-41.

(4) Nagatani, H.; Iglesias, R. A.; Fermín, D. J.; Brevet, P. F.; Girault, H. H. J. Phys. Chem. B 2000, 104, 6869-6876. 